\title{
Stages of behavioural change after direct- to-consumer disease risk profiling: study protocol of two integrated controlled pragmatic trials
}

\author{
Kelly F. J. Stewart ${ }^{1 *}$ (D, Anke Wesselius ${ }^{1}$, Annemie M. W. J. Schols ${ }^{2}$ and Maurice P. Zeegers ${ }^{1,3}$
}

\begin{abstract}
Background: The incidence and prevalence of chronic diseases have reached epidemic proportions during the last decades and are not expected to diminish. Chronic diseases increasingly affect younger individuals too, with over $40 \%$ of all deaths due to non-communicable diseases occurring before the age of 70 . This has led to the development of information services aimed at preventive health care, such as Health Potential ${ }^{\circledR}$. This counselling service estimates a personal disease risk of a carefully selected list of preventable common chronic diseases that have both a genetic and a lifestyle component of development. The results are delivered face-to-face by a lifestyle counsellor, simultaneously stimulating initial steps towards behaviour change. This information can assist in lifestyle decision-making.

Methods/design: The primary aim is to study the effect of the Health Potential ${ }^{\circledR}$ service on change in lifestyle behaviour in distinguishable customer populations. The secondary aims are (1) to study the effect of the Health Potential ${ }^{\circledR}$ service on determinants of behaviour change, (2) to study the effect of additional lifestyle counselling on behaviour change and determinants thereof, and (3) to describe the characteristics of the Health Potential ${ }^{\circledR}$ customer. The study consists of two integrated designs: (A) a two-armed non-randomised controlled pre-test/ post-test trial (1.5:1 ratio), followed by (B) a two-armed randomised controlled pre-test/post-test trial (1:1 ratio), resulting in three study arms. Participants are clients of local prevention clinics, purchasing a personalised health check (PHC; intervention condition), consisting of Health Potential ${ }^{\circledR}$ and a general health check, or the general health check alone (GHC; control condition) (part A). PHC participants will be randomised to receive four additional lifestyle counselling sessions over a period of 3 months (part B).
\end{abstract}

Discussion: This research can provide valuable insights into the effectiveness of and possible ways forward in the field of personalised prevention making use of lifestyle interventions enriched with modern genetic advancements.

Trial registration: Nederlands Trial Register, NTR6289 and NTR6288. Registered on 24 February 2017.

Keywords: Personalised medicine, Personalised prevention, Trials, Direct-to-consumer genetics, Lifestyle epidemiology, Genetic epidemiology, Community genetics, Health promotion

\footnotetext{
* Correspondence: k.stewart@maastrichtuniversity.nl

'Department of Complex Genetics, NUTRIM School of Nutrition and

Translational Research in Metabolism, Maastricht University, Maastricht, The

Netherlands

Full list of author information is available at the end of the article
}

(c) The Author(s). 2018 Open Access This article is distributed under the terms of the Creative Commons Attribution 4.0 International License (http://creativecommons.org/licenses/by/4.0/), which permits unrestricted use, distribution, and reproduction in any medium, provided you give appropriate credit to the original author(s) and the source, provide a link to the Creative Commons license, and indicate if changes were made. The Creative Commons Public Domain Dedication waiver (http://creativecommons.org/publicdomain/zero/1.0/) applies to the data made available in this article, unless otherwise stated. 


\section{Background}

The incidence and prevalence of chronic diseases have reached epidemic proportions during the last decades and are not expected to decrease or diminish. In 2012, 38 million people died as a result of a non-communicable disease, of which $82 \%$ were due to cardiovascular diseases, diabetes, cancer and chronic respiratory diseases [1]. This number is projected to increase to 52 million deaths by 2030 [2]. Of particular concern is the fact that over $40 \%$ of all NCD deaths occurred before the age of 70 in 2012 [1]. As a result of these developments, we must expect an increasing economic burden and reduction of quality of life in many societies, among both affected people and their social environment.

Most, if not all, common chronic diseases develop over a lifetime as a result of interplay between genetic predisposition and the accumulation of lifetime exposures to environmental and behavioural factors. According to the World Health Organization (WHO), unhealthy diet, physical inactivity, tobacco use and harmful alcohol consumption are among the most important modifiable causes of chronic disease worldwide [3]. For example, harmful alcohol use and tobacco use account for $12 \%$ of all deaths worldwide, and an additional 19\% is accounted for by unhealthy diet and physical inactivity [3]. As these are all modifiable, great potential exists for prevention or delay of chronic diseases, resulting in a renewed necessity for and interest in disease prediction and prevention [4].

The fact that most chronic diseases seem to be preventable and the neoliberal political climate in many countries have contributed to the rise of personal responsibility for health [5]. Individuals are more and more expected to strive to obtain and maintain their best possible health. In order to do so, they need to be optimally informed and make their own risk-benefit analyses. This has led to an exponential growth in services aiming at assisting in informing and assisting individuals to make informed decisions. Another such approach is through genetic testing [6]. Although one has no control over their genetic make-up, knowledge of genetic predispositions could provide the opportunity for personalised prevention strategies and may serve in health-related decision-making $[7,8]$.

Personal genomic testing (PGT) uses genetic variations in individuals to estimate personal disease risks and sometimes several other genetically determined phenotypes such as food intolerances or drug metabolism [9]. PGT has become popular and accessible as a result of rapid advances in the field of DNA analysis techniques. This has made genome analysis possible at relatively low costs, with PGT companies like 23andMe dropping their price from US\$999 in 2007 to US\$199 in 2017 ([10], https://www.23andme.com/). These services are mostly offered to the general population direct-to-consumer (DTC), meaning without interference of a physician. PGT may help individuals change their behaviour towards more health-promoting lifestyle through identification of an increased disease risk [11]. An important assumption of the success of this strategy is that the identification of increased disease risk could directly influence risk reduction behaviours [8, 12, 13]. However, research has shown that this assumption mostly does not apply in all populations or that the effects are minor in general populations $[13,14]$.

Limitations of this idea that PGT may facilitate behaviour change are that, firstly, probability and genetic data are difficult to comprehend without counselling $[15,16]$ and understanding is strongly influenced by several factors such as the format of delivery [17]. Secondly, disease risks are not solely determined by either lifestyle or genetic factors, but both [18]. Thirdly, disease risk information alone may not be motivating enough for individuals to change behaviour and therefore additional lifestyle intervention and motivational counselling may be necessary to help individuals change and maintain behaviour [7].

To address these shortcomings, a new disease risk information service has been developed: Health Potential ${ }^{\circ}$. This service estimates a personal disease risk of a carefully selected list of preventable common chronic diseases that have both a genetic and a lifestyle component of development. The results are delivered face-to-face by a certified lifestyle counsellor, simultaneously stimulating initial steps towards behaviour change. Because previous research has shown that not all health care professionals feel confident in interpreting and communicating DTC-GT results to their patients or clients $[19,20]$, all Health Potential $^{\circ}$ counsellors are trained to ensure confidence and skill.

The effect of this new personalised service will be researched in two integrated studies, one observational study and one intervention trial, comparing the service to a general health check only. The primary aim of the study is to study the effect of the Health Potential ${ }^{\circledR}$ advice on change in lifestyle behaviour in distinguishable customer populations. The secondary aims are (1) to study the effect of the Health Potential ${ }^{\bullet}$ service on determinants of behaviour change, (2) to study the effect of additional lifestyle counselling on behaviour change and determinants thereof, and (3) to study the characteristics of the Health Potential ${ }^{\triangleright}$ customer.

\section{Methods/design}

Study design

This study consists of two integrated trials. The first trial is a non-randomised two-armed controlled pre-test/ post-test superiority trial (part A). Of one of those arms, participants can enter the second trial, which is a 
randomised controlled pre-test/post-test superiority trial (part B), on the condition that they consent to participate. In order to obtain sufficient participants for part B, participants in part A will be distributed in a 1.5:1 ratio. Participants will be randomised at a 1:1 ratio in part $B$. This results in three study arms (Fig. 1). However, due to eligible participants of part A potentially not consenting to participation in part B, study arm 2 can again be considered as two study arms: participants in arm 2a have consented to participate in part B whereas participants in $2 b$ have not (see Fig. 1 for a visualisation).

\section{Rationale for the study design}

The study is designed in a way to reflect the 'real world' situation in which the participants are not randomised for part A and all participants pay a (reduced) fee for the services. The reason behind this approach is that we expect a certain level of 'pre-motivation' and possibly other different personal characteristics (e.g. personality, socioeconomic status, income, level of education, gender, age) among clients of the Health Potential $^{\odot}$ service, particularly when an additional 'barrier' exists of a fee that has to be paid for the service.

Due to the nature and cost of the products, and consistent with Rogers' theory of early adopters [21], the study population is likely to consist of (apparently) healthy individuals aged 18 and over, expected to have higher social status, higher financial resources, and higher education, and who are relatively health conscious.

\section{Study setting}

Part A of the study takes place through online questionnaires, which participants can fill out at home. The additional lifestyle counselling will be offered through certified counsellors located in South-Limburg, The Netherlands.

\section{Participants and recruitment}

Participants for part A of the study will be recruited from the regular customers at local prevention clinics who have purchased one of the following products:

- Product 1: personalised health check (PHC). The PHC consists of the Health Potential ${ }^{\oplus}$ service (future health) and a general health check of the customer's current health.

- Product 2: a general health check of current health only (GHC).

Potential participants will be informed of the study by the local responsible investigator of each clinic. Eligible participants for part A are apparently healthy individuals aged 18 and over, with a Dutch language level similar to language proficiency level B2, not currently following any prescribed dietary or other guidelines, not pregnant or trying to become pregnant, authorised to make autonomous decisions, able to independently visit the counselling clinic, and have Internet access and an email address. Participants who purchased product 1 are eligible to take part in part B of the study. Enrolment will be open for 1 year.

\section{Sample size and power calculation}

The sample size calculation is based on the proportion of participants who have changed their behaviour (being in the action/maintenance stage of behaviour change; see 'Study parameters') for at least three of the received advices at follow-up in the overall analysis. The type I error rate was set at 0.05 and an additional 20\% was added to compensate for loss to follow-up in part A.

Part A: The smallest difference is expected between arms 2 and 3. It is estimated that with $(291+20 \%=) 350$ participants in each arm, part A has a power of $80 \%$ to detect a proportion of 0.3 in arm 2 versus a proportion of 0.2 in arm 3.

Part B: Study arm 1 will be compared to arm 2a. It is then estimated that with $(160+20 \%=) 192$ participants in each arm, part B has a power of $80 \%$ to detect a proportion of 0.45 in arm 1 versus a proportion of 0.3 in arm $2 \mathrm{a}$. As in part A 548 participants will be included in the PHC condition, this will give a margin of $(548-384=) 164$ for participants not consenting to participate in part B. Together this results in a total number of participants of $(192+350+350=) 892$.

\section{Blinding, randomisation and treatment allocation}

Participants who purchased the PHC and who consented to participate in part $\mathrm{B}$ will be electronically randomised to receive the additional lifestyle counselling. Randomisation will be stratified by local clinic, and block randomisation will be used with block sizes of 4 within each stratum. The health coach will subsequently implement the appropriate intervention.

Although blinding is not possible for the participants and the health counsellors delivering the intervention, the data analyses will be performed in a blinded format through preparation of the dataset by an independent researcher.

\section{Investigational behavioural intervention}

Part A does not contain an intervention. In part B, the participant receives additional lifestyle counselling. The lifestyle counselling consists of four additional personal face-to-face sessions with a purpose-trained lifestyle counsellor. The counselling follows four phases matching four core questions [22] and is delivered using principles of motivational interviewing $[23,24]$ : 


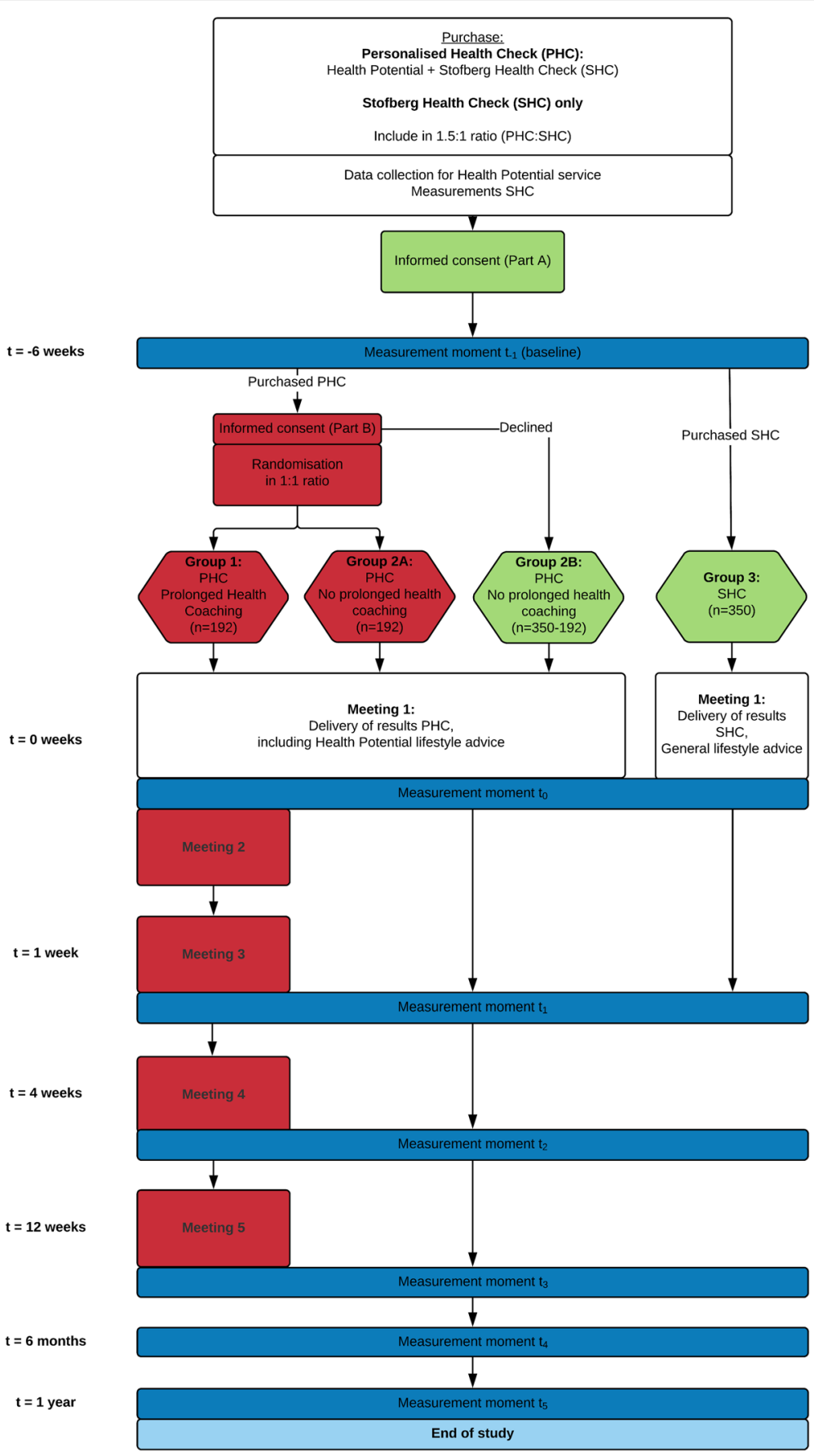

Fig. 1 Conceptual framework

- Counselling phase 1: "Am I at an increased risk because of my lifestyle?"

- Counselling phase 2: "Which choices are suitable for me?"

- Counselling phase 3: "How do I translate my choices to behaviour?"
- Counselling phase 4: "How can I maintain my change in behaviour?"

All lifestyle counselling sessions are done by the same certified lifestyle counsellors for one participant. The sessions take place at $t=0$ week, $t=1$ week, $t=4$ weeks 
and $t=12$ weeks (see Fig. 1, sessions 2-5) and will last approximately 45-60 min per session.

\section{Study parameters}

To study the effect of Health Potential $^{\circledR}$ on behaviour change, a conceptual framework has been developed (Fig. 2), based on a previously proposed framework for PGT by Bloss et al. [8] and the I-change model [25]. The framework consists of two steps that are relevant for eventual behaviour change: (1) purchasing Health Potential $^{\circ}$ and (2) behaviour change as a result of Health Potential ${ }^{\circ}$. Determinants included in both steps are based on the literature on PGT [20, 26-36] and the I-change model [37].

All parameters (Table 1) are measured using online questionnaires, as part of part A of the study, and are saved in a coded format. Measurements take place at $t=-6$ weeks (baseline), $t=0$ week, $t=1$ week, $t=4$ weeks, $t=12$ weeks, $t=6$ months and $t=1$ year (Figs. 3 and 4 ).

\section{Statistical analysis}

Where appropriate, the analyses will be performed according to an intention-to-treat (ITT) approach (part B only) and per-protocol approach. Data will be analysed using STATA (StataCorp. Stata Statistical Software, College Station, TX: StataCorp LP). Statistical significance is assumed at a $p$ value of 0.05 , and no correction for multiple testing will be applied.

\section{Ethical considerations}

Due to the nature of the researched population and the very limited risks associated with the study, no data safety monitoring board or safety committee is deemed necessary. No interim analyses will be performed.

The full protocols, for both parts $\mathrm{A}$ and $\mathrm{B}$, can be found on https://dataverse.nl/dataset.xhtml?persistentId=hdl:10411/XKOM8H identifier 10411/XKOM8H (see also Additional file 1).

\section{Discussion}

To our best knowledge, this is the first trial investigating such a wide range of determinants with regard to the effect of a disease prevention service based on both genetic and lifestyle components of disease risk. The study will contribute to the debate on whether genetic prevention services can be effective in improving lifestyle behaviour in certain customer groups and will help identify actionable determinants that contribute to an increased effect. Health Potential $^{\circledR}$ will support the individual in making informed decisions about their health and lifestyle, which will become increasingly important in the current paradigm of personal responsibility for one's health.

The study has several strengths and risks. Firstly, the pragmatic approach of the study will give a good indication of the effect in a real-life situation after implementation, resulting in a small theory-practice gap. However, on the one hand, it may also result in greater heterogeneity and thereby a dilution of the effect. On the other

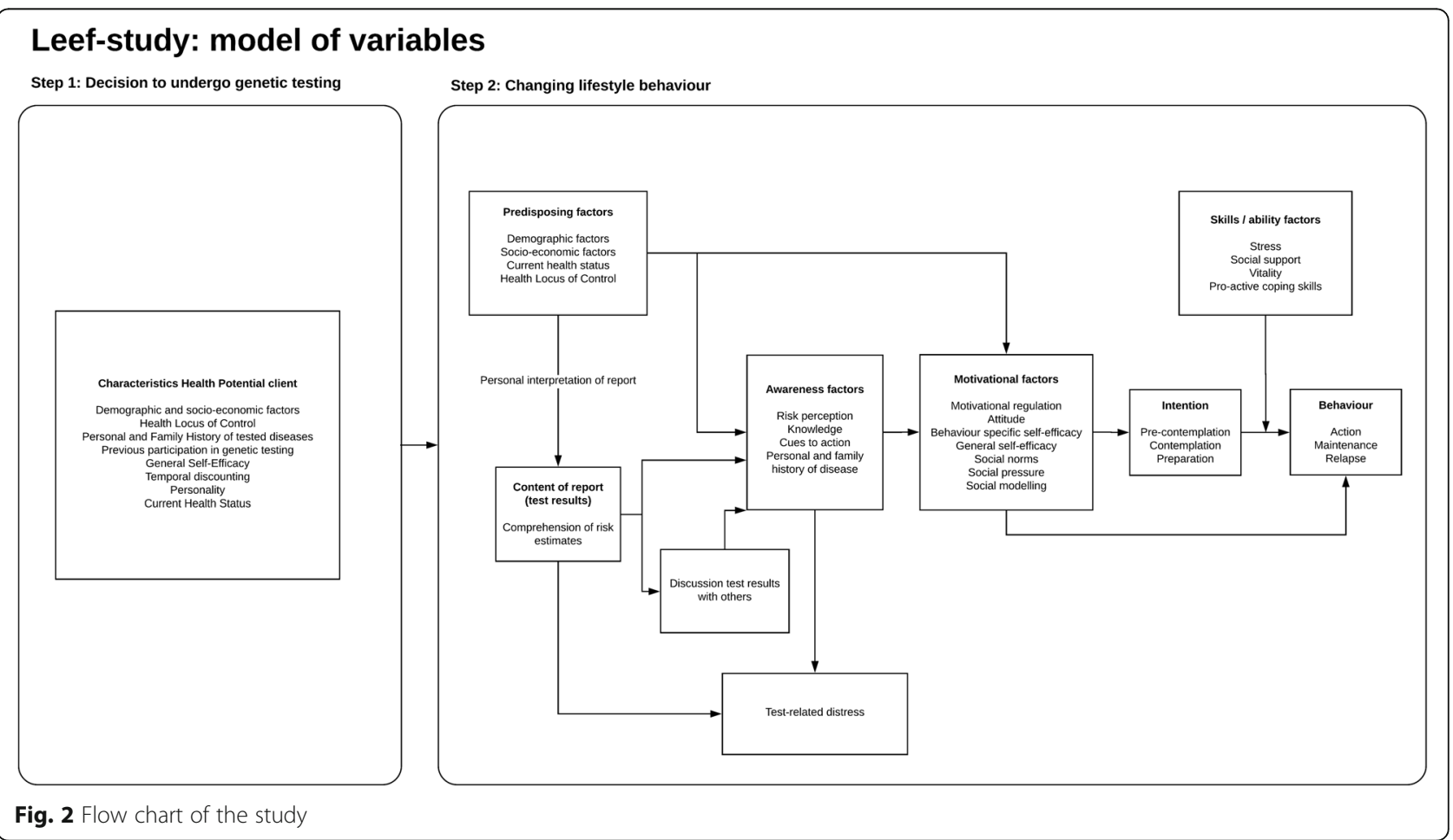


Table 1 Outcome parameters and other parameters

Outcome parameters

Behaviour change (stage of change)

Behaviour change (verification)

Motivational regulation

Attitude

Behaviour-specific self-efficacy

Risk perception

Perceived stress

Discussion of test results with health professionals and/or family and friends

Test-related distress (arms 1 and 2 only)
Questionnaire containing 1 question per advice received to determine the current stage of change (transtheoretical model (Fig. 4) [43-45]).

Physical activity: the validated Dutch version of the International Physical Activity Questionnaire (IPAQ) [46].

Smoking: questions on current smoking behaviour and quantity of smoking.

Dietary and alcohol intake: questions on regular intake of all food groups and alcoholic consumptions, for which advice is received by the participant. Body weight and waist circumference: measured at home by the participant, following detailed instructions and using the same weighing scale each time.

Validated Treatment Self-Regulation Questionnaire (TSRQ) [47], translated into Dutch. This questionnaire has been modified to ask motivational regulation with regard to the 'advice given' and 'healthy lifestyle'.

Questionnaire consisting of 7 Likert scale items on outcome expectations, 16 Likert scale items on the reasons for (not) undergoing testing by Health Potential ${ }^{\circledast}$ 50 Likert scale items on the attitude towards five primary lifestyle behaviours, 1 Likert scale item on the importance of preventing disease, and 6 items on the evaluation of the Health Potential ${ }^{\circledR}$ report.

Questionnaire which was developed using the 'Guide for constructing selfefficacy scales' by Bandura [48]. It includes one self-efficacy question for each advice given in which the participant indicates on a scale of $0-100 \%$ how sure they are of their ability to follow the advice.

Likert scale questions on the perceived probability of getting and severity [37] of each of the diseases included in the standard Health Potential ${ }^{\circledR}$ service.

Dutch translation of the validated 14-item Perceived Stress Scale (PSS) [49].

Multiple-answer question in which the participant can indicate with whom the results were discussed.

Dutch translation $[50,51]$ of the validated Impact of Event Scale (IES), which has been used previously to study test-related distress after genetic testing for common disease risk [39].
Table 1 Outcome parameters and other parameters (Continued)

\begin{tabular}{|c|c|}
\hline \multicolumn{2}{|l|}{ Other study parameters } \\
\hline $\begin{array}{l}\text { Self-reported } \\
\text { health status }\end{array}$ & $\begin{array}{l}\text { Dutch translation of the validated RAND } \\
\text { 36-ltem Short Form Health Survey, V2 } \\
\text { (SF-36 V2) }[52,53] \text {. }\end{array}$ \\
\hline Health locus of control & $\begin{array}{l}\text { Dutch translation of the validated } \\
\text { Multidimensional Health Locus of } \\
\text { Control (MHLC) Scale }[54,55] \text {. }\end{array}$ \\
\hline $\begin{array}{l}\text { Comprehension of risk } \\
\text { estimates } \\
\text { (arms } 1 \text { and } 2 \text { only) }\end{array}$ & $\begin{array}{l}\text { Questions based on the questions } \\
\text { used by Kaufman et al. [56]. }\end{array}$ \\
\hline $\begin{array}{l}\text { Genetic knowledge } \\
\text { (arms } 1 \text { and } 2 \text { only) }\end{array}$ & $\begin{array}{l}\text { Dutch translation of the questions } \\
\text { as used by Carere et al. [57]. }\end{array}$ \\
\hline Cue to action & $\begin{array}{l}\text { Two Likert scale questions on whether } \\
\text { the participant felt the Health Potential } \\
\text { report and the general health check } \\
\text { were a cue to action. }\end{array}$ \\
\hline $\begin{array}{l}\text { Personal and family } \\
\text { history of tested diseases }\end{array}$ & $\begin{array}{l}\text { Questionnaire asking about personal } \\
\text { and family history. }\end{array}$ \\
\hline General self-efficacy & $\begin{array}{l}\text { Validated Dutch General Self-Efficacy } \\
\text { Scale (DGSES) [58]. }\end{array}$ \\
\hline $\begin{array}{l}\text { Social modelling, } \\
\text { social support }\end{array}$ & $\begin{array}{l}\text { One Likert scale question per } \\
\text { advice received. }\end{array}$ \\
\hline Social support & $\begin{array}{l}\text { One Likert scale question per lifestyle } \\
\text { domain (diet, alcohol, physical activity, } \\
\text { smoking, body weight). }\end{array}$ \\
\hline $\begin{array}{l}\text { Pro-active } \\
\text { coping skills }\end{array}$ & $\begin{array}{l}\text { Validated Utrechtse Pro-actieve Coping } \\
\text { Competenties (UPCC) questionnaire [59]. }\end{array}$ \\
\hline Vitality & Validated Vita-16 [60]. \\
\hline $\begin{array}{l}\text { Previous participation } \\
\text { in genetic testing }\end{array}$ & Two yes/no questions. \\
\hline Temporal discounting & $\begin{array}{l}\text { Validated 10-item Delaying Gratification } \\
\text { Inventory short form, translated into } \\
\text { Dutch (DGl-10) [61]. }\end{array}$ \\
\hline Personality & Validated Dutch IPIP-50 [62]. \\
\hline
\end{tabular}

hand, the expected population of mostly early adopters might again reduce heterogeneity. Secondly, due to this pragmatic approach and the relatively high cost of genetic testing, the study population can be expected to be a selective group of higher educated individuals with a relatively high income. As health and lifestyle are associated with socio-economic position, services like Health Potential $^{\circ}$ may contribute to increasing health inequalities when the test is purchased personally. In the future, employers or municipalities may subsidise such tests for their employees or certain groups of inhabitants, which could diminish this effect. Finally, the outcomes include a wide range of actionable determinants of behaviour change, which will allow us to investigate through which determinants the effect on behaviour change is achieved. Knowing these explanatory variables may then inform us about the determinants that need to be addressed further in order to achieve a greater effect on behaviour change, direct recruitment strategies, and guide further development of genetic testing services. In addition, identification of 


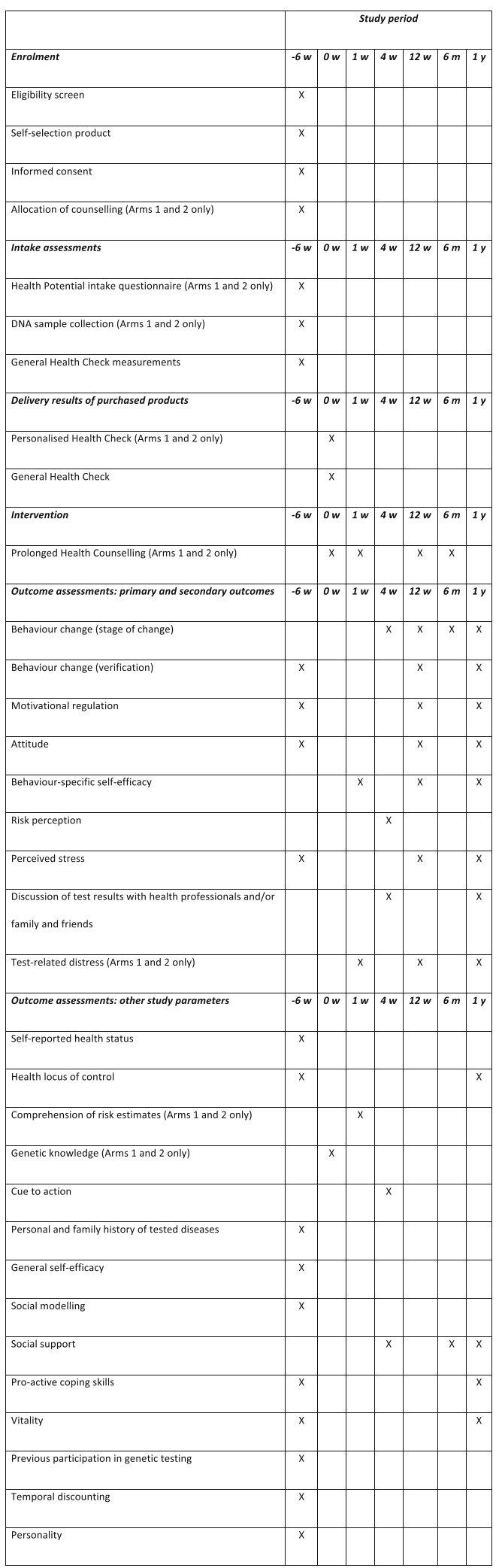

Fig. 3 Schedule of enrolment, interventions and assessment

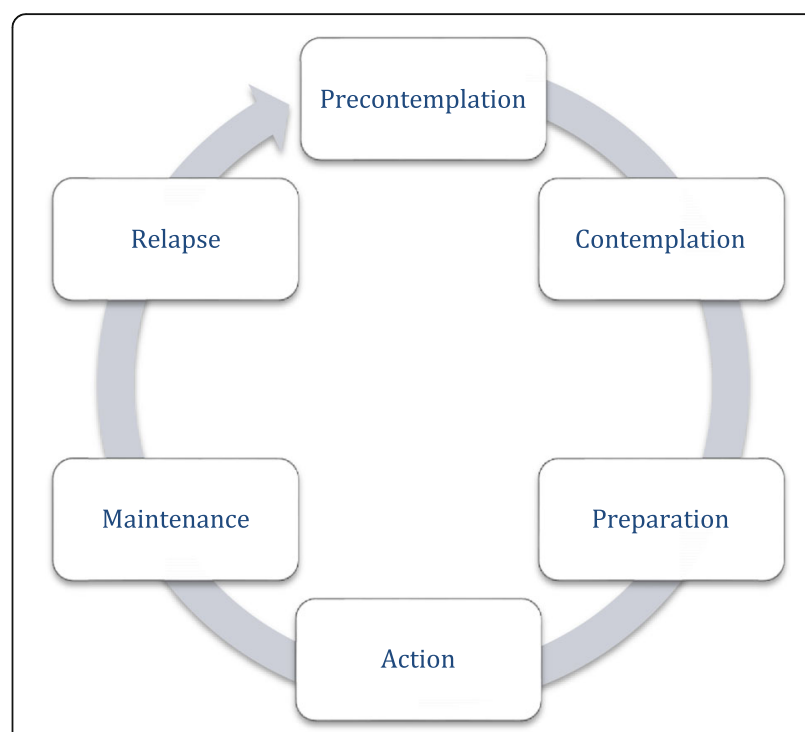

Fig. 4 Transtheoretical model [43-45]

specific groups of customers in which an effect is or is not seen will further help to tailor strategies.

PGT services, such as Health Potential ${ }^{\circ}$, also carry some risks and benefits for the consumer. Firstly, because of the high psychological impact of genetic testing for diseases with a strong genotype-phenotype interaction, it is under debate whether genetic testing for common disease risk also leads to too high levels of distress among participants. However, recent studies have suggested that the level of distress is minimal $[7,14,38,39]$. The close contact between client and coach is hypothesised to further reduce any worry or distress and in case any serious distress arises, this can be recognised at an early stage and appropriate action can be taken. Whether this holds true will also be examined in this study. Secondly, a serious risk of PGT services is misinterpretation of test results by consumers [16]. Consequences of misinterpretation may be undermined motivation (e.g. interpreting a reduced risk as definitely not getting the disease), unnecessary worry and distress, and a burden on the health care system through requesting unnecessary medical tests and asking for help from health care professionals to interpret the results $[7,40]$. To address the issue, the Health Potential ${ }^{\circ}$ report has been based on literature on communication of disease risks [41] and the results are explained to the client face-to-face by a certified Health Potential $^{\circ}$ coach. Finally, Health Potential ${ }^{\circ}$ has a strong connection with her end users, including both coaches and clients. In the development of the supporting software and the communication of results, end users have been involved. This involvement is crucial for the acceptance and therefore viability of a service [42].

This research can provide valuable insights into the effectiveness of PGT services. These findings can be used 
in the development and improvement of lifestyle interventions enriched with modern genetic advancements.

\section{Trial status}

The trial is currently in preparation.

\section{Additional file}

Additional file 1: SPIRIT 2013 checklist: recommended items to address in a clinical trial protocol and related documents. (DOC $123 \mathrm{~kb}$ )

\section{Abbreviations}

DTC: Direct-to-consumer; GHC: General health check; METC : Medisch Ethische Toetsings Commissie (Medical Research Ethics Committee (MREC)) PGT: Personal genomic testing; PHC: Personal health check; WHO: World Health Organization

\section{Acknowledgements}

The authors wish to thank Stofberg Group for their assistance in planning the logistical aspects of the study and Operis for their support in the certification course of the Health Potential ${ }^{\circledR}$ counsellors.

\section{Funding}

This project was funded by the Maastricht University Interfaculty Programme 'Eatwell'. The funder had no influence in the development of the protocol.

\section{Availability of data and materials}

Data sharing is not applicable to this article as no datasets were generated or analysed during the current study.

\section{Authors' contributions}

All authors (KS, AW, AS and MZ) contributed substantially to the conception and design of the study and ethical submissions. KS drafted the manuscript, which was critically revised by AW, MZ and AS. AW, AS and MZ obtained funding. All authors read and approved the final manuscript and have given approval for the publication of this paper.

\section{Ethics approval and consent to participate}

The protocol has been approved by the METC AzM/UM (numbers 16-4-077 and 163014) and is registered on www.trialregister.nl on 24 February 2017 with registration numbers NTR6289 and NTR6288. Informed consent will be obtained from each participant for both part A and part B separately.

\section{Competing interests}

Health Potential may become a spin-off service from Maastricht University led by Prof. Maurice Zeegers.

\section{Publisher's Note}

Springer Nature remains neutral with regard to jurisdictional claims in published maps and institutional affiliations.

\section{Author details}

'Department of Complex Genetics, NUTRIM School of Nutrition and Translational Research in Metabolism, Maastricht University, Maastricht, The Netherlands. ${ }^{2}$ Department of Respiratory Medicine, NUTRIM School of Nutrition and Translational Research in Metabolism, Maastricht University, Maastricht, The Netherlands. ${ }^{3}$ CAPHRI School for Public Health and Primary Care, Maastricht University, Maastricht, The Netherlands.

Received: 8 June 2017 Accepted: 6 April 2018

Published online: 19 April 2018

\section{References}

1. Alwan A. Global status report on noncommunicable diseases 2010. Geneva: World Health Organization; 2011.

2. Projections of mortality and causes of death, 2015 and 2030. http://www.who. int/healthinfo/global_burden_disease/projections/en/. Accessed 5 Jan 2017.
3. World Health Organization. Global health risks: mortality and burden of disease attributable to selected major risks. Geneva: World Health Organization; 2009.

4. Singh AR. Modern medicine: towards prevention, cure, well-being and longevity. Mens Sana Monographs. 2009;8(1):11.

5. Resnik DB. Responsibility for health: personal, social, and environmental. J Med Ethics. 2007;33(8):444-5.

6. Resnik DB. Genetics and personal responsibility for health. New Genet Soc. 2014;33(2):113-25

7. Stewart K, Schreurs M, Wesselius A, Schols A, Zeegers M. Behavioural changes and psychological responses after receiving direct-to-consumer genetic test results: a systematic review and meta-analysis. J Comm Genet. 2017. (in press)

8. Bloss CS, Madlensky L, Schork NJ, Topol EJ. Genomic information as a behavioral health intervention: can it work? Per Med. 2011;8(6):659-67.

9. Gollust SE, Wilfond BS, Hull SC. Direct-to-consumer sales of genetic services on the Internet. Genet Med. 2003;5(4):332-7.

10. Another $\$ 50 \mathrm{M}$ richer, 23 andMe drops its price to $\$ 99$ permanently. But will the average dude buy in? https://techcrunch.com/2012/12/11/23andnotme/. Accessed 23 Mar 2017.

11. Offit K. Personalized medicine: new genomics, old lessons. Hum Genet. 2011:130(1):3-14.

12. Henrikson NB, Bowen $D$, Burke W. Does genomic risk information motivate people to change their behavior. Genome Med. 2009;1(4):37.

13. Leventhal H, Benyamini $Y$, Brownlee S, Diefenbach M, Leventhal EA, PatrickMiller L, Robitaille C. Illness representations: theoretical foundations. Percept Health IIIn. 1997;2:19-46.

14. Roberts JS, Ostergren J. Direct-to-consumer genetic testing and personal genomics services: a review of recent empirical studies. Curr Genet Med Rep. 2013;1(3):182-200.

15. Lanie AD, Jayaratne TE, Sheldon JP, Kardia SL, Anderson ES, Feldbaum M, Petty EM. Exploring the public understanding of basic genetic concepts. Genet Couns. 2004:13(4):305-20.

16. McGrath SP, Coleman J, Najjar L, Fruhling A, Bastola DR. Comprehension and data-sharing behavior of direct-to-consumer genetic test customers. Public Health Genomics. 2016;19(2):116-24.

17. Fausset CB: Comprehension of health risk probabilities: the roles of age, numeracy, format, and mental representation. 2012.

18. Al-Zalabani AH, Stewart KFJ, Wesselius A, Schols MWJ, Zeegers MP. Modifiable risk factors for the prevention of bladder cancer: a systematic review of meta-analyses. Eur J Epidemiol. 2016;31(9):811-51.

19. Christensen KD, Vassy JL, Jamal L, Lehmann LS, Slashinski MJ, Perry DL, Robinson JO, Blumenthal-Barby J, Feuerman LZ, Murray MF, et al. Are physicians prepared for whole genome sequencing? A qualitative analysis. Clin Genet. 2016;89(2):228-34.

20. Goldsmith L, Jackson L, O'Connor A, Skirton H. Direct-to-consumer genomic testing: systematic review of the literature on user perspectives. Eur J Hum Genet. 2012;20(8):811-6.

21. Rogers EM. Diffusion of innovations. 5th ed. New York: Simon and Schuster; 2003

22. Lak M, Bijma M. Leefstijlcoaching: kernvragen bij gedragsverandering. Houten: Bohn Stafleu van Loghum; 2012.

23. Miller WR. Motivational interviewing with problem drinkers. Behav Psychother. 1983;11(02):147-72.

24. Rubak S, Sandbæk A, Lauritzen T, Christensen B. Motivational interviewing: a systematic review and meta-analysis. $\mathrm{Br} J$ Gen Pract. 2005:55(513):305-12.

25. De Vries H, Mesters I, van't Riet J, Willems K, Reubsaet A. Motives of Belgian adolescents for using sunscreen: the role of action plans. Cancer Epidemiol Biomark Prev. 2006;15(7):1360-6.

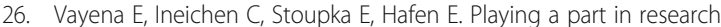
university students' attitudes to direct-to-consumer genomics. Public Health Genomics. 2014;17(3):158-68

27. Sweeny K, Legg AM. Predictors of interest in direct-to-consumer genetic testing. Psychol Health. 2011;26(10):1259-72.

28. Cherkas LF, Harris JM, Levinson E, Spector TD, Prainsack B. A survey of UK public interest in Internet-based personal genome testing. PLoS One. 2010;5(10):e13473.

29. Su Y, Howard HC, Borry P. Users' motivations to purchase direct-toconsumer genome-wide testing: an exploratory study of personal stories. J Comm Genet. 2011:2(3):135-46.

30. Vayena E, Gourna E, Streuli J, Hafen E, Prainsack B. Experiences of early users of direct-to-consumer genomics in Switzerland: an exploratory study. Public Health Genomics. 2012;15(6):352-62. 
31. McGowan ML, Fishman JR, Lambrix MA. Personal genomics and individual identities: motivations and moral imperatives of early users. New Genet Soc 2010;29(3):261-90.

32. McBride CM, Alford SH, Reid RJ, Larson EB, Baxevanis AD, Brody LC. Characteristics of users of online personalized genomic risk assessments: implications for physician-patient interactions. Genet Med. 2009;11(8):582-7.

33. Gollust SE, Gordon ES, Zayac C, Griffin G, Christman MF, Pyeritz RE, Wawak L, Bernhardt BA. Motivations and perceptions of early adopters of personalized genomics: perspectives from research participants. Public Health Genomics. 2012;15(1):22-30.

34. Mavroidopoulou V, Xera E, Mollaki V. Awareness, attitudes and perspectives of direct-to-consumer genetic testing in Greece: a survey of potential consumers. J Hum Genet. 2015;60(9):515-23.

35. McGuire AL, Diaz CM, Wang T, Hilsenbeck SG. Social networkers' attitudes toward direct-to-consumer personal genome testing. Am J Bioeth. 2009; $9(6-7): 3-10$

36. Bloss CS, Ornowski L, Silver E, Cargill M, Vanier V, Schork NJ, Topol EJ. Consumer perceptions of direct-to-consumer personalized genomic risk assessments. Genet Med. 2010;12(9):556-66.

37. de Vries H, Mesters I, Van de Steeg H, Honing C. The general public's information needs and perceptions regarding hereditary cancer: an application of the Integrated Change Model. Patient Educ Couns. 2005; 56(2):154-65.

38. Bloss CS, Schork NJ, Topol EJ. Effect of direct-to-consumer genomewide profiling to assess disease risk. N Engl J Med. 2011;364(6):524-34.

39. Bloss CS, Wineinger NE, Darst BF, Schork NJ, Topol EJ. Impact of direct-toconsumer genomic testing at long term follow-up. J Med Genet. 2013; https://doi.org/10.1136/jmedgenet-2012-101207.

40. Skirton $\mathrm{H}$, Jackson L, Goldsmith L, O'Connor A. Are health professionals ready for direct-to-consumer genetic and genomic testing? Per Med. 2013; 10(7):673-82.

41. Lautenbach DM, Christensen KD, Sparks JA, Green RC. Communicating genetic risk information for common disorders in the era of genomic medicine. Annu Rev Genomics Hum Genet. 2012;14:491-513.

42. Jaspers MWM. A comparison of usability methods for testing interactive health technologies: methodological aspects and empirical evidence. Int J Med Inform. 2009;78(5):340-53.

43. Prochaska JO, DiClemente CC, Velicer WF, Ginpil S, Norcross JC. Predicting change in smoking status for self-changers. Addict Behav. 1985;10(4):395-406.

44. Prochaska JO, Goldstein MG. Process of smoking cessation. Implications for clinicians. Clin Chest Med. 1991;12(4):727-35.

45. Prochaska JO, Velicer WF. The transtheoretical model of health behavior change. Am J Health Promot. 1997;12(1):38-48.

46. Craig $C L$, Marshall AL, Sjostrom M, Bauman AE, Booth ML, Ainsworth BE, Pratt M, Ekelund U, Yngve A, Sallis JF, et al. International physical activity questionnaire: 12-country reliability and validity. Med Sci Sports Exerc. 2003; 35(8):1381-95.

47. Ryan RM, Connell JP. Perceived locus of causality and internalization: examining reasons for acting in two domains. J Pers Soc Psychol. 1989; 57(5):749.

48. Bandura A. Guide for constructing self-efficacy scales. Self-efficacy Beliefs Adolesc. 2006:5:307-37.

49. Cohen S, Kamarck T, Mermelstein R. A global measure of perceived stress. J Health Soc Behav. 1983;24(4):385-96.

50. Brom D, Kleber RJ. De Schok Verwerkings Lijst [The Dutch version of the Impact of Event Scale]. Nederlands Tijdschrift voor de Psychologie. 1985;40: $164-8$.

51. van der Ploeg E, Mooren T, Kleber RJ, van der Velden PG, Brom D. Construct validation of the Dutch version of the impact of event scale. Psychol Assess. 2004;16(1):16

52. van der Zee Kl, Sanderman R, Heyink JW, de Haes H. Psychometric qualities of the RAND 36-Item Health Survey 1.0: a multidimensional measure of general health status. Int J Behav Med. 1996;3(2):104-22.

53. van der Zee Kl, Sanderman R. Het meten van de algemene gezondheidstoestand met de RAND-36. Een handleiding [Measuring general health status with the RAND-36. Users manual]. Groningen: Groningen Northern Center of Health Care Research; 1993.

54. Wallston KA, Wallston BS, DeVellis R. Development of the multidimensional health locus of control (MHLC) scales. Health Educ Behav. 1978:6(1):160-70.
55. Halfens R, Philipsen $H$. Een gezondheidsspecifieke beheersingsorientatieschaal validiteit en betrouwbaarheid van de MHLC. T Soc Gezondheidsz. 1988;66:399-403.

56. Kaufman DJ, Bollinger JM, Dvoskin RL, Scott JA. Risky business: risk perception and the use of medical services among customers of DTC personal genetic testing. J Genet Couns. 2012;21(3):413-22.

57. Carere DA, Kraft P, Kaphingst KA, Roberts JS, Green RC, Group PGS. Consumers report lower confidence in their genetics knowledge following direct-to-consumer personal genomic testing. Genet Med. 2015;18(1):65-72.

58. Teeuw $B$, Schwarzer $R$, Jerusalem M: Dutch adaptation of the general selfefficacy scale. 1994. http://userpage.fu-berlin.de/ health/dutch.htm. Accessed 23 Oct 2015

59. Bode C, Thoolen B, Ridder D. Het meten van proactieve copingvaardigheden. PSEG. 2008;36(2):81-91.

60. Strijk JE, Wendel-Vos GCW, Picavet HSJ, Hofstetter H, Hildebrandt VH. Wat is vitaliteit en hoe is het te meten? Tijdschrift voor gezondheidswetenschappen. 2015;93(1):32-40.

61. Hoerger M, Quirk SW, Weed NC. Development and validation of the Delaying Gratification Inventory. Psychol Assess. 2011;23(3):725.

62. Goldberg LR. The development of markers for the Big-Five factor structure. Psychol Assess. 1992;4(1):26.

Ready to submit your research? Choose BMC and benefit from

- fast, convenient online submission

- thorough peer review by experienced researchers in your field

- rapid publication on acceptance

- support for research data, including large and complex data types

- gold Open Access which fosters wider collaboration and increased citations

- maximum visibility for your research: over $100 \mathrm{M}$ website views per year

At BMC, research is always in progress.

Learn more biomedcentral.com/submissions 